\title{
Abetalipoproteinaemia. A case report with pathological studies
}

\author{
G. M. YUILL \\ M.B., Ch.B., M.R.C.P., B.Sc. \\ C. SchOLZ* \\ M.B., B.S., F.R.C.P.A. \\ R. G. LASCELleS \\ M.D., F.R.C.P., D.P.M. \\ Departments of Neurology and *Neuropathology, The University of Manchester
}

\begin{abstract}
Summary
The clinical and pathological features of a case of abetalipoproteinaemia in a 38-year-old patient are described in detail. A feature not previously recorded was a marked reduction in the velocity of ocular horizontal saccadic movements. Pathological studies revealed an active chronic demyelinating process. The patient showed no response to large doses of vitamin $E$. The rationale for this therapy, and the possible reasons for its failure are discussed.
\end{abstract}

\section{Introduction}

This report describes a case of abetalipoproteinaemia (ABLP) seen in the Neurological Unit at Manchester Royal Infirmary. The patient is aged 38 years and is therefore one of the oldest cases on record. The majority of previous cases have been in children.

The syndrome was first described by Bassen and Kornzweig (1950). Since then, approximately twenty-five cases have been documented, and the subject was reviewed in detail by Kayden (1972).

ABLP has three major features: (1) a malabsorption syndrome commonly presenting in early childhood in which the jejunal biopsy shows prominent villi with characteristic overloading of the enterocyte with triglyceride; (2) development of a peripheral neuropathy, cerebellar and pyramidal tract disease, progressive visual deterioration, optic atrophy and pigmentary degeneration of the retina; (3) the presence of acanthocytes in the peripheral blood, absence of $\beta$-lipoprotein in the serum, and a low chylomicron count which does not rise after a fatty meal. The lipid structure of the red cell membrane is also abnormal. Fat malabsorption results in low circulating levels of the fat-soluble vitamins $A$ and $E$. Only rarely, however, does a deficiency of vitamin $\mathrm{K}$ cause an overt bleeding problem. Rickets and osteomalacia have not been described. Isselbacher

Correspondence: Dr G. M. Yuill, Consultant Neurologist, Crumpsall Hospital, Manchester 8. et al. (1964) review the abnormal biochemistry in detail.

In view of the presence of malabsorption, a wide variety of dietary supplements and of parenteral replacement of potentially deficient factors have been employed. The majority of such therapies have been unsuccessful, although it would appear that mild fat restriction and massive vitamin E dosage may be of value (Isselbacher et al., 1964; Schwarz et al., 1963; Di-George, Mabry and Auerbach, 1961; Lloyd and Muller, 1972).

\section{Case report}

A 38-year-old male was born of unrelated parents. As an infant he suffered from diarrhoea. At the age of 7 he began omitting milk from his diet, and after this the diarrhoea improved. When 11 years of age he noticed slight difficulty in seeing in the dark. When 16 years of age he was seen by a consultant neurologist who noted the following abnormalities: mild limitation of convergence; absence of deep tendon reflexes in the lower limbs. There was mild ataxia in the lower limbs. Both plantars were extensor. There was impairment of vibration sense below the knees and reduction of joint position sense in the right foot only. A diagnosis of an atypical form of Friedreich's ataxia was made. He was refused for military service on account of these disabilities. He was next seen 22 years later (1972) in the Neurological Unit at Manchester Royal Infirmary. He complained of 18 months' increasing weakness of the upper and lower limbs and of unsteadiness. On examination, the blood pressure was $140 / 80$ $\mathrm{mmHg}$, and the pulse was $80 / \mathrm{min}$ and regular. The heart, lungs, abdominal viscera and genitalia were normal. There was a mild flexion deformity of right fourth and fifth fingers. The abnormalities on neurological examination were as follows: there was bilateral optic atrophy and retinitis pigmentosa. The visual acuity was $1 / 60$ in the right eye and $3 / 60$ in the left eye. There were large bilateral central scotomata 


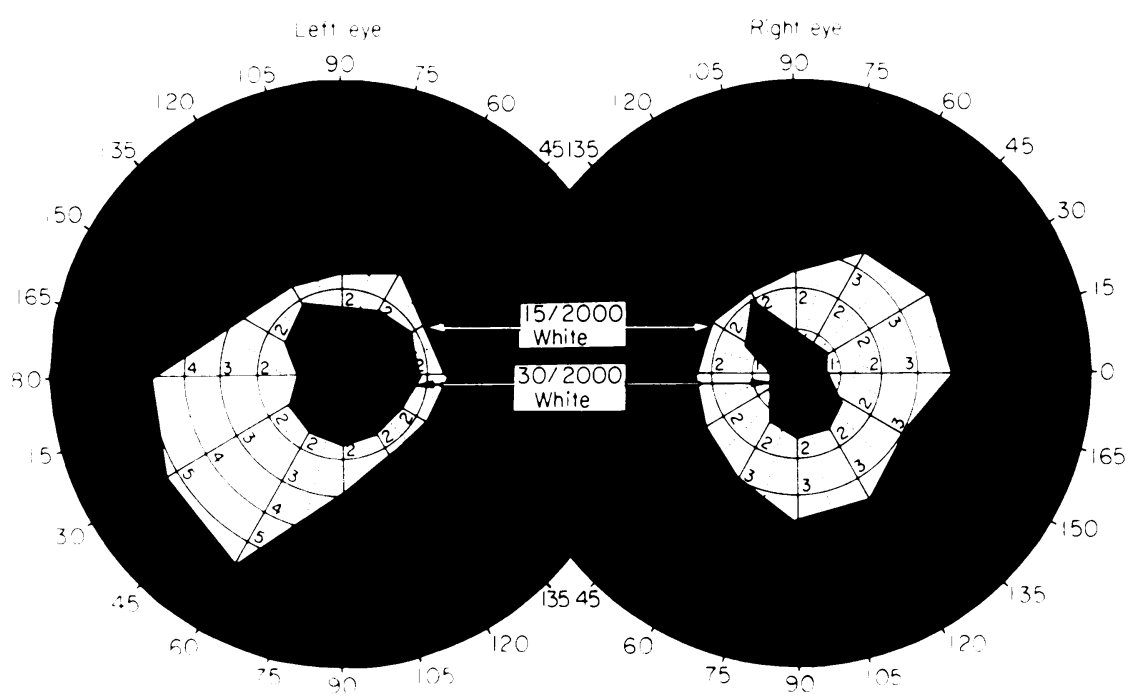

Fici. 1. The patient's visual fields.

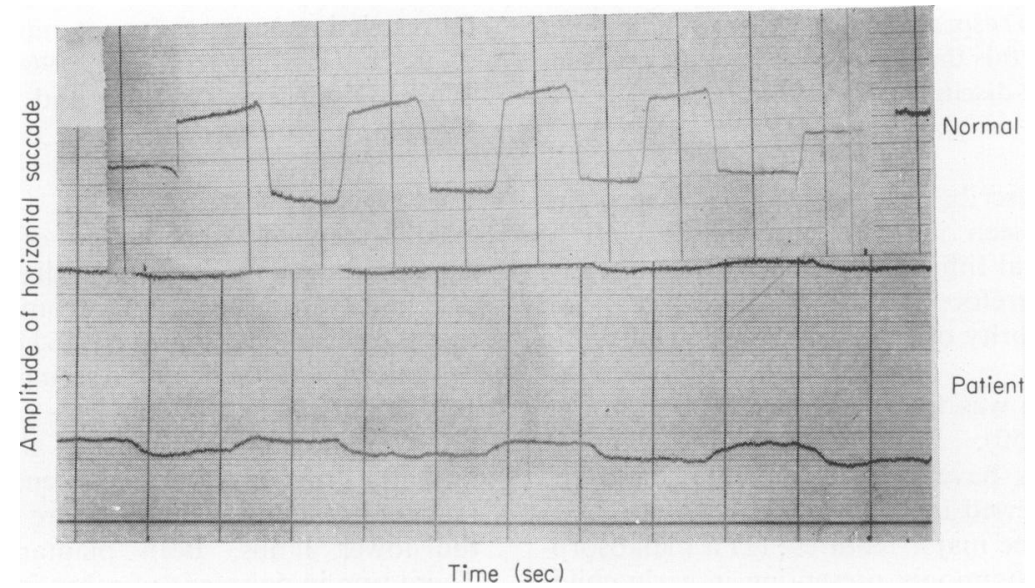

FIG. 2. Graphical demonstration of the amplitude of horizontal ocular saccadic movements in the patient and in a normal subject.

and moderate constrictions of the peripheral visual fields (Fig. 1). The external ocular movements were normal in amplitude. There was slight limitation of convergence. There was marked reduction of the velocity of horizontal saccadic movements (Fig. 2). There was mild bilateral facial weakness. In the upper limbs there was slight weakness of the deltoids, mild intention tremor and reduction of light touch and two point discrimination over the fingers of both hands. In the lower limbs there was mild weakness of the hip flexors and of the dorsiflexors of the feet. The knee and ankle jerks were absent and both plantar responses were extensor. There was moderate reduction of sensation to light touch, vibration and position below the knees. There was moderate heelshin ataxia and his gait was broad-based and ataxic.

A clinical diagnosis of an hereditary ataxia was made but the precise classification of the disorder was recognized when acanthocytes were seen in the peripheral blood.

\section{Further progress}

He has been treated for the last 6 months with a diet supplemented with medium chain triglycerides $10 \mathrm{~g}$ and vitamin $\mathrm{E} 2 \mathrm{~g}$ orally daily. There has been further deterioration in his condition during the time he has taken these supplements. 

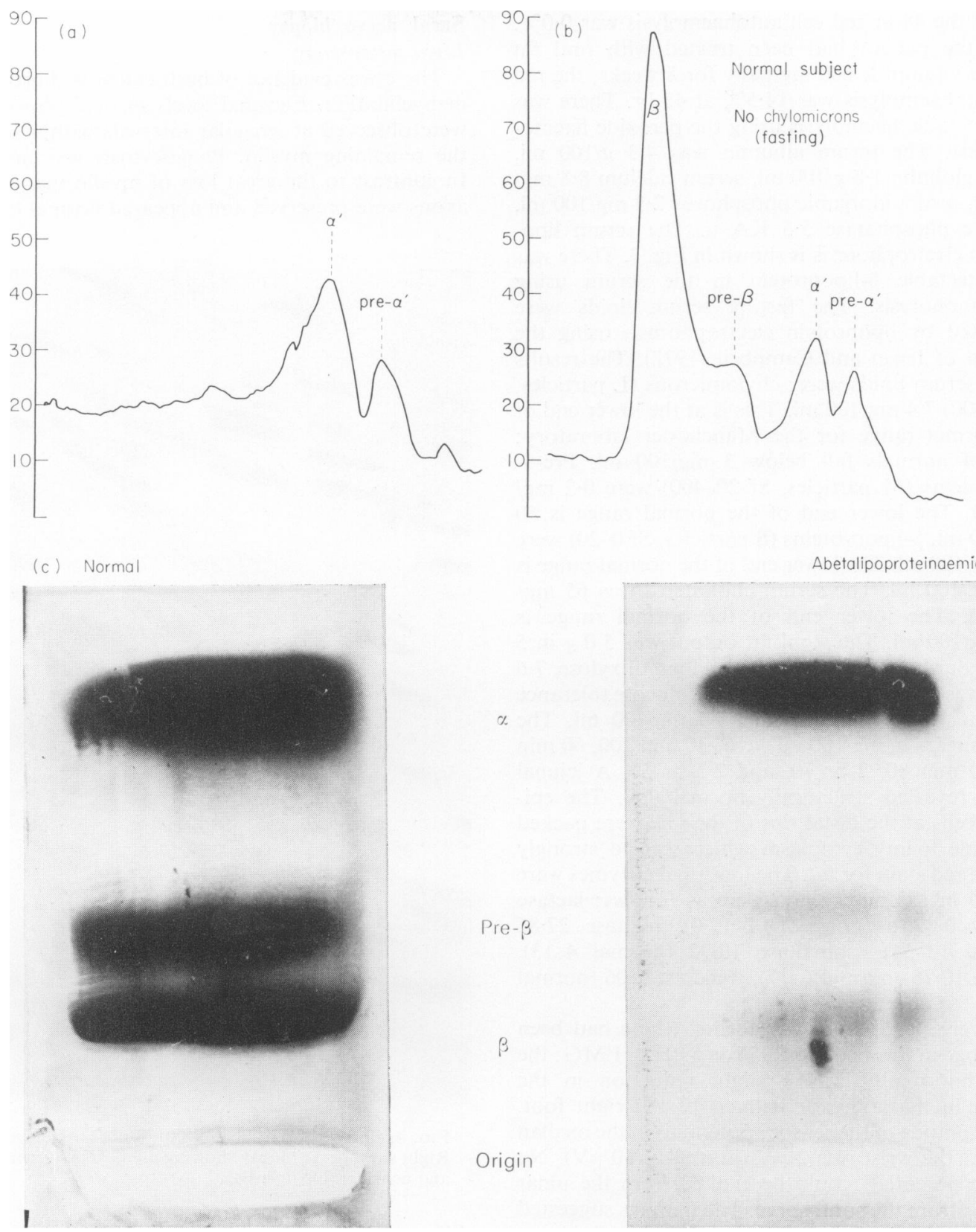

Abetalipoproteincemia

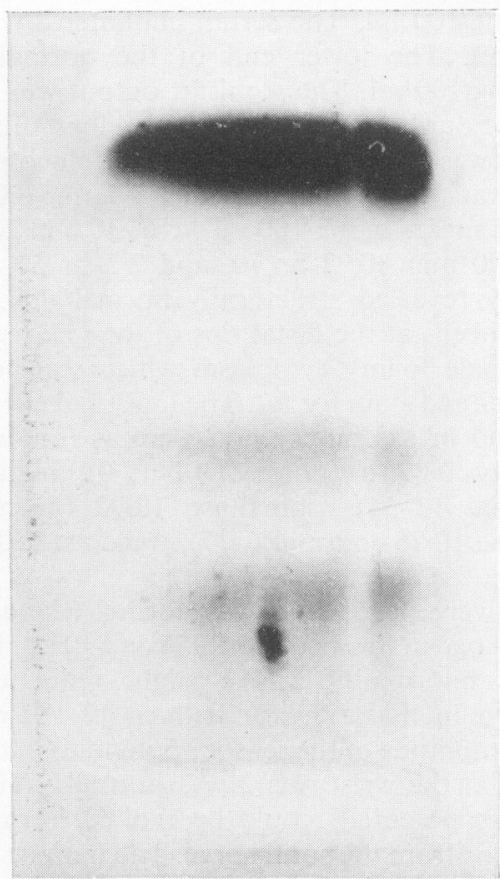

FIG. 3. (a) The patient's serum lipoprotein electrophoretic densitometric scan. (b) A normal subject's serum lipoprotein electrophoretic densitometric scan. (c) The patient's serum lipoprotein electrophoretic strip on the right, and a normal subject's serum lipoprotein electrophoretic strip on the left.

\section{Investigations}

Haemoglobin $12.8 \mathrm{~g} / 100 \mathrm{ml}$, WBC $4400 / \mathrm{mm}^{3}$, ESR (Westergren) $1 \mathrm{~mm}$ in the first hour. The blood film showed a marked degree of acanthocytosis, the reticulocyte count was $3.6 \%$. The serum iron was
$75 \mu \mathrm{g} / 100 \mathrm{ml}$ (20\% saturation); serum $\mathrm{B}_{12} 230 \mathrm{pg} /$ $100 \mathrm{ml}$, serum folic acid $8 \mathrm{ng} / 100 \mathrm{ml}$. The prothrombin time was $15 \mathrm{sec}$ (control $13 \mathrm{sec}$ ). There was $50 \%$ red cell autohaemolysis at $48 \mathrm{hr}$ incubation (control $0 \cdot 2-2 \cdot 0 \%$ ). After the addition of $\alpha$-tocopherol to the 
system the $48-\mathrm{hr}$ red cell autohaemolysis was $0.0 \%$. After the patient had been treated with oral fat soluble vitamin E $600 \mathrm{mg}$ daily for 8 weeks, the red cell autohaemolysis was $14.5 \%$ at $48 \mathrm{hr}$. There was no detectable haemolysis using the peroxide haemolysis test. The serum albumin was $4.3 \mathrm{~g} / 100 \mathrm{ml}$, serum globulin $1.8 \mathrm{~g} / 100 \mathrm{ml}$, serum calcium $8.8 \mathrm{mg} /$ $100 \mathrm{ml}$, serum inorganic phosphorus $2.3 \mathrm{mg} / 100 \mathrm{ml}$, alkaline phosphatase $5.5 \mathrm{KA}$ u. The serum lipoprotein electrophoresis is shown in Fig. 3. There was no detectable $\beta$-lipoprotein in the serum using immunophoresis. The fasting serum lipids were separated by lipoprotein electrophoresis using the method of Irwin and Campbell (1972). The results of the serum lipids were: chylomicrons (L particles, Sf > 400) $7.4 \mathrm{mg} / 100 \mathrm{ml}$. This is at the lower end of the normal range for the Manchester laboratory; $10 \%$ of normals fall below $3 \mathrm{mg} / 100 \mathrm{ml}$. Pre- $\beta$ lipoproteins (M particles, Sf 20-400) were $0.2 \mathrm{mg} /$ $100 \mathrm{ml}$. The lower end of the normal range is 50 $\mathrm{mg} / 100 \mathrm{ml}$. $\beta$-lipoproteins (S particles, Sf 0-20) were $125 \mathrm{mg} / 100 \mathrm{ml}$. The lower end of the normal range is $250 \mathrm{mg} / 100 \mathrm{ml}$. The serum cholesterol was $65 \mathrm{mg} /$ $100 \mathrm{ml}$. The lower end of the normal range is $140 \mathrm{mg} / 100 \mathrm{ml}$. The stool fat output was $5.0 \mathrm{~g}$ in 5 days. Four hours after a $25-\mathrm{g}$ oral load of xylose, $7 \cdot 6$ $\mathrm{g}$ of it was excreted in the urine. The glucose tolerance test was: fasting blood sugar $85 \mathrm{mg} / 100 \mathrm{ml}$. The blood sugars in $\mathrm{mg} / 100 \mathrm{ml}$ were: $30 \mathrm{~min} 200,60 \mathrm{~min}$ $120,90 \mathrm{~min} 80,2 \mathrm{hr} 70$, and $2 \cdot 5 \mathrm{hr} 50$. A jejunal biopsy revealed structurally normal villi. The epithelial cells at the distal tips of the villi were packed with pale foamy cytoplasm which stained strongly with oil red stain for fat. The intestinal enzymes were assayed in the biopsy and were as follows: lactase activity $0.09 \mathrm{u}$ (normal 0.2-19.0), maltase 27.86 (normal 13-54), isomaltase 10.92 (normal 4-13), sucrase 10.75 (normal 6-17), trehalase 2.06 (normal 1-10).

A twelve lead ECG was normal (there had been no change in this between 1956 and 1973). EMG: the only abnormality was a slight reduction in the pattern in the abductor hallucis of the right foot. The amplitude of the sensory potentials in the median nerve at the wrist was $2 \mu \mathrm{V}$ (normal $>10 \mu \mathrm{V}$ ). No sensory potentials could be evoked from the ulnar nerve or from the sural nerve. The findings suggested a peripheral neuropathy. The cerebrospinal fluid was clear, colourless and under normal pressure. It contained no cells, the protein was $25 \mathrm{mg} / 100 \mathrm{ml}$, and the Lange curve was normal. The WR was negative in the blood and cerebrospinal fluid. The serum vitamin $\mathrm{E}$ levels were $130 \mu \mathrm{g} / 100 \mathrm{ml}$ (normal 520 $1140 \mu \mathrm{g} / 100 \mathrm{ml})$. Plain X-rays of the chest, hands, feet, cervical, thoracic and lumbar spine were normal. The urine screening tests for porphyrins were negative.

\section{Sural nerve biopsy}

\section{Light microscopy}

There was evidence of both extensive fibrosis and demyelination. Elevated levels of acid phosphatase were observed at irregular intervals within some of the remaining myelin. Phagocytosis was not seen. In contrast to the great loss of myelin many of the axons were preserved and appeared normal (Fig. 4).

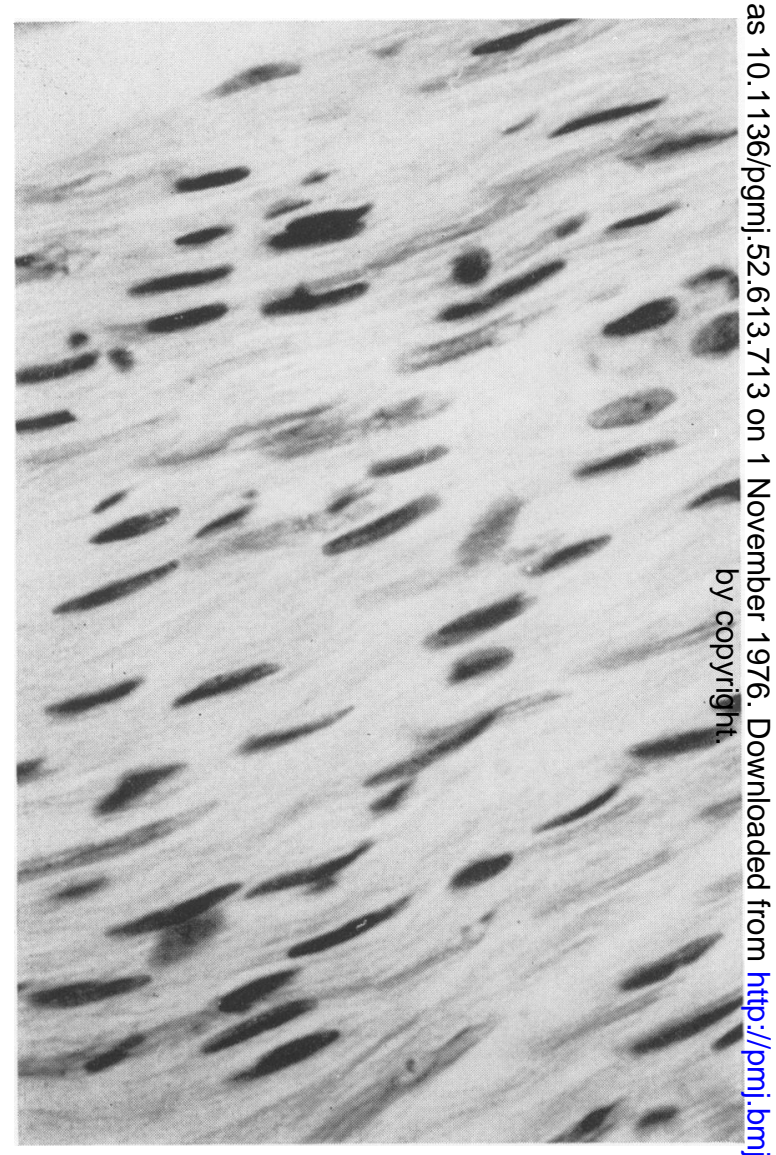

Fig. 4. Photomicrograph $(\times 400)$. Solochrome cyanine. Right sural nerve biopsy showing a few myelin remnants and considerable fibrosis.

\section{Electron microscopy}

The material was fixed in glutaraldehyde. There was uniform myelination to a maximum of thirty rings. Myelin figures were prominent both within axons and in Schwann cell cytoplasm between lamellae. The electronmicrographs of the myelin show changes considered to be thickening, occasional splitting and fragmentation of the interperiod lines (Fig. 5). It is possible however that these appearances are due to processing artefacts. Schmidt Lantermann 


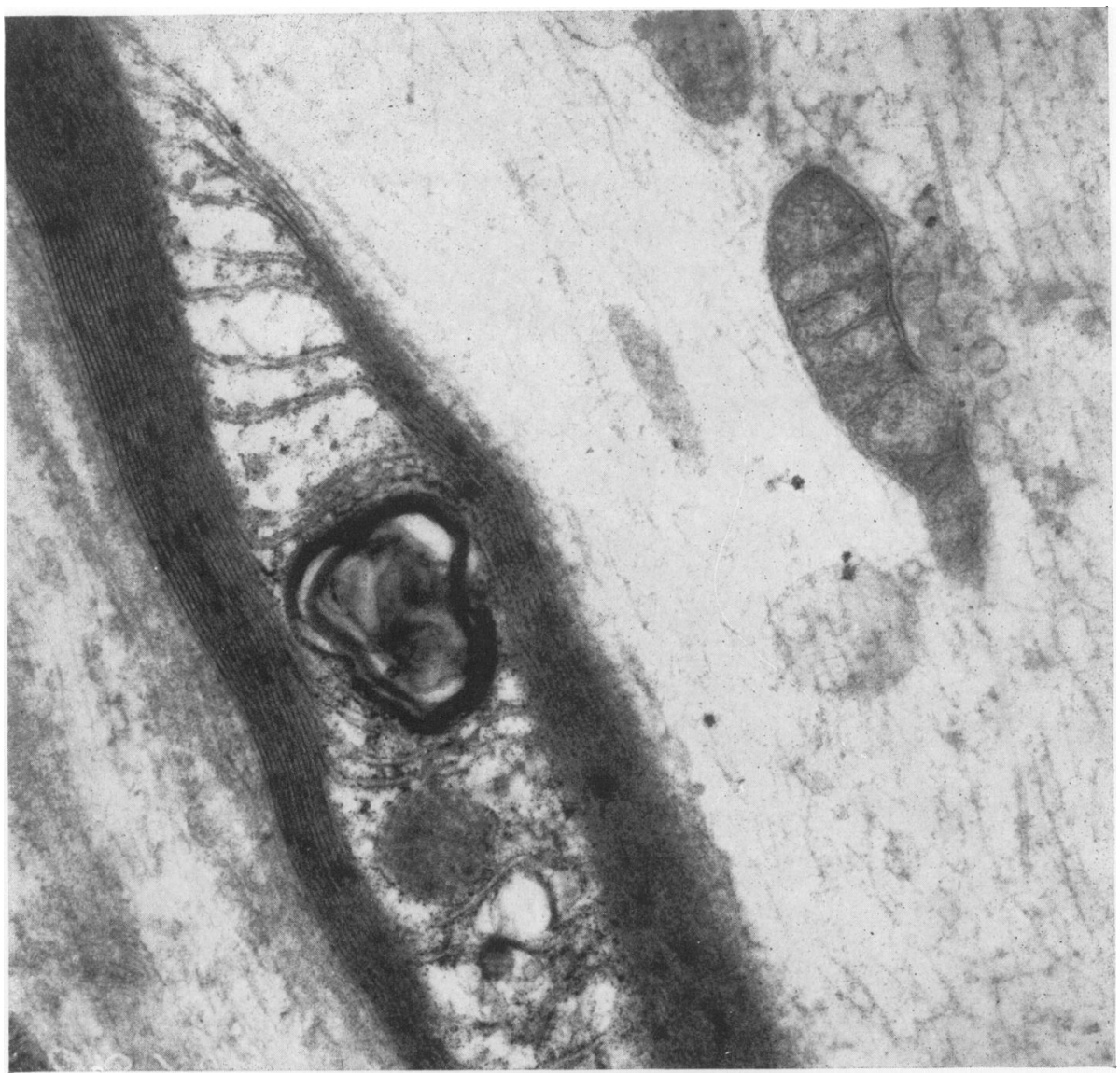

FIG. 5. Electron micrograph $(\times 75,000)$. Right sural nerve biopsy showing fragmentation of the myelin. There is also thickening and fragmentation of the interperiod lines.

clefts were seen more commonly than is usual. They contained occasional myelin figures and frequently showed very prominent desmosomal stacks (Fig. 6).

\section{Family study}

The patient's daughter, brother, paternal uncle and aunt were examined. They were clinically normal and all had normal blood films.

\section{Discussion \\ Clinical aspects}

The unusual feature of the present case is his survival to the age of 38 years. Dische and Porro (1970) and Sobrevilla, Goodman and Kane (1964) reported death from cardiac failure in one case each, and Kayden (1972) stated there had been six early deaths in patients with the condition. The present patient has no signs or symptoms of cardiac disease and he has a normal electrocardiograph. It is unknown to what else his relative longevity can be attributed, as in all other respects his condition seems identical to that of other documented cases.

The only abnormality which may be definitely attributed to the low serum vitamin $E$ levels was the increased red cell autohaemolysis, as this was reduced both by vitamin $\mathrm{E}$ in vitro and in vivo, as reported by Kayden, Silber and Kossman (1965). The relationship of the neurological deficit to the low serum vitamin $E$ level is not established. Low levels of serum vitamin $E$ are known to occur in several other conditions. In none of these conditions, however, are specific symptoms and signs known to be solely attributable to deficiency of vitamin $\mathrm{E}$, nor do haematological or neurological abnormalities appear similar to those seen in ABLP.

One feature of this condition is that steatorrhoea usually precedes the development of neurological abnormalities by several years, as in this case.

It is hard to reconcile the slow evolution of the neural deficit with the theory that malabsorption of 


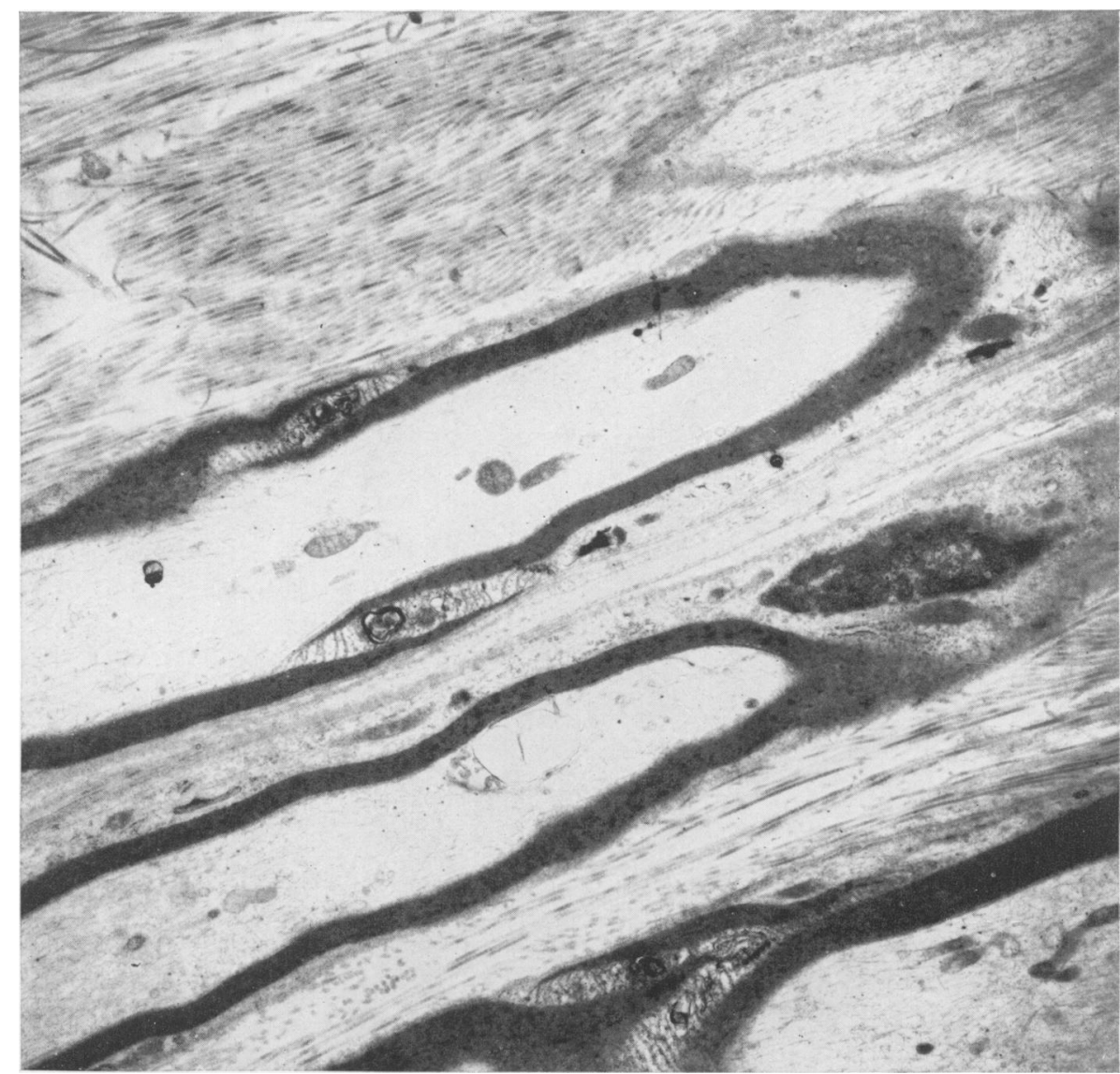

FIG. 6. Electronmicrograph $(\times 7,200)$. Right sural nerve biopsy. There are two Schmidt-Lantermann clefts. One contains a desmosomal stack and the other myelin figures.

vitamin A, vitamin $\mathrm{E}$, or some other fat-soluble factor is responsible for the neuropathic process, as most vitamin deficiencies causing neuropathies do so fairly quickly. Furthermore, if the theory that a fat-soluble deficiency was responsible is correct, then one would expect that dietary supplementation would prevent, or at least ameliorate, the neurological deterioration. Lees and Ahrens (1969) demonstrated that no improvement in glyceride transport occurred after transfusion of $\beta$-lipoprotein. They transfused an 11-year-old boy suffering from ABLP with plasma from a subject with hyper- $\beta$-lipoproteinaemia over a period of 4 days. The recipient's plasma $\beta$-lipoprotein cholesterol rose from zero to $285 \mathrm{mg} / 100 \mathrm{ml}$. However, his plasma triglycerides did not rise above $22 \mathrm{mg} / 100 \mathrm{ml}$ and they could not find any evidence of formation of chylomicrons or of pre- $\beta$-lipoprotein, neither did the patient's dietary fat intolerance improve. They did not observe any change in the morphology of his red blood cells. They made no comment on his nervous system.
They concluded that lack of $\beta$-lipoprotein is not a cause of deficient glyceride transport.

However, Lloyd and Muller (1972) reported that treatment with large doses of oral $\alpha$-tocopherol acetate may halt the progression of the retinopathy and possibly also reverse some of the neurological deficit.

One reason for absence of neurological response to vitamin $\mathrm{E}$ therapy is that only partial neurological recovery may be expected once significant damage to nervous tissue has occurred. It is attractive to hope that since a defect of the red cell (manifesting as increased autohaemolysis) can be corrected by vitamin E, some defect of neuronal structure might be similarly amenable to correction. There are as yet insufficient data to answer this question. Although most of the neurological features of this case resemble those of previously documented cases, slowness of ocular saccade is not mentioned in other reports. In two cases autopsy studies were performed. In each there was demyelination of the pyramidal 
and spinocerebellar tracts, and patchy demyelination of the peripheral nerves. In the present study there is evidence of demyelination in peripheral nerve. It is presumed that demyelination in the brain stem caused this abnormality of ocular movement.

\section{Pathological aspects}

The pathological features seen in the peripheral nerve suggest a demyelinating process which, in view of the presence of fibrosis, seems to be of considerable duration. The presence of myelin figures indicates that the process is still active.

Cooper and Gulbrandsen (1971) showed that in the red corpuscle membrane in ABLP sphingomyelin replaces phosphatidyl serine, that the sphingomyelin/phosphatidyl serine ratio is reversed and that there is an increased percentage of cholesterol. When sphingomyelin (average chain length 17.9 carbon units) replaces phosphatidyl serine (average chain length 20.7 carbon units) the result is a slight condensation of the lipid structure. This causes narrowing of the interperiod lines on electron microscopy as can be seen in this case (the interperiod distance had been reduced by $4.5 \mathrm{~nm}$ approximately $25 \%$, this is outside the limit of error of the examination-10\%).

It is possible that when such alteration of a biochemical structure occurs the altered myelin is liable to excessive breakdown. O'Brien (1967) also showed alteration of lipid content of myelin in this condition.

\section{Conclusions}

In the case described in this report, no improvement occurred in response to treatment with medium chain triglycerides and massive doses of vitamin $\mathrm{E}$. It is thought that this is because irreversible neurological damage had been sustained during the course of a long-standing disease. It is not considered that this represents a serious criticism of the potential value of such therapy, which seems of considerable benefit when used in children (Lloyd and Muller, 1972).

It is considered a mistake to try to interrelate the three major biochemical abnormalities to each other on a cause and effect basis, and the work of Lees and Ahrens (1969), to a limited extent, seems to support this view. Of course, it is not denied that a malabsorption syndrome might produce a set of purely secondary abnormalities of which, for instance, vitamin $\mathrm{E}$ deficiency might be an important feature. Although it is known that the essential abnormality in ABLP is an inability to synthetize $\beta$-globulin (needed to make $\beta$-liproprotein, pre- $\beta$-lipoprotein, and chylomicrons) it is thought that the same failure may be directly responsible for the faulty production of part of the structure of both the red blood cell and the neurone. In this connection, the work of Aminoff (1972), Levine, Estes and Looney (1968) and Critchley, Clark and Wikler (1968) is of interest as it suggests the possibility of a common genetic linkage between some structural elements of both neurones and red blood cells.

\section{Acknowledgments}

We wish to thank Professor P. O. Yates for his advice on pathological aspects of the case; Dr J. E. MacIver for his help with haematological investigation; Dr I. M. S. Wilkinson who measured and recorded the eye movements; Dr S. L. Ching and Mr C. J. Seneviratne who performed the lipoprotein electrophoresis.

\section{References}

Aminoff, M.J. (1972) Acanthocytosis and neurological disease. Brain, 95, 749.

Bassen, F.A. \& KoRnzweig, A.L. (1950) Malformation of the erythrocytes in a case of atypical retinitis pigmentosa. Blood, 5, 381 .

CoOPer, R.A. \& Gulbrandsen, C.L. (1971) The relationship between serum lipoproteins and red cell membrane in abetalipoproteinaemia. Deficiency of lecithin cholesterol acyltransferase. Journal of Laboratory and Clinical Medicine, 78, 323.

Critchley, E.M.R., Clark, D.B. \& Wikler, A. (1968) Acanthocytosis and neurological disorder without abetalipoproteinaemia. Archives of Neurology'(Chicago), 18, 134.

Di-George, A.M., Mabry, C.C. \& Auerbach, V.H. (1961) A specific disorder of lipid transport (acanthocytosis). Treatment with intravenous lipids. American Journal of Diseases of Children, 102, 580.

Dische, M.R. \& Porro, R.S. (1970) The cardiac lesions in Bassen-Kornzweig syndrome. Report of a case with autopsy findings. American Journal of Medicine, 49, 568.

IrWin, W.C. \& Camprell, D.J. (1972) Agarose gel electro. phoresis of lipoproteins. In: Standard Methods of Clinical Chemistry, Vol. 7. American Association of Clinical Chemists (Edited by G. R. Cooper and J. Stanton-King). Academic Press, New York and London.

Isselbacher, K.J., Scheig, R., Plotkin, G.R. \& Caulfied, J.B. (1964) Congenital betalipoprotein deficiency: an hereditary disorder involving a defect in the absorption and transport of lipids. Medicine (Baltimore), 43, 347.

KAYDEN, H.J. (1972) Abetalipoproteinaemia. Annual Review of Medicine, 23, 285.

Kayden, H.J., Silber, R. \& Kossman, C.E. (1965) The role of vitamin B deficiency in the abnormal autohaemolysis of acanthocytosis. Transactions of the Association of American Physicians, 78, 334.

LeEs, R.S. \& Ahrens, E.H., JR (1969) Fat transport in abetelipoproteinaemia. The effects of repeated infusions of beta lipoprotein rich plasma. New England Journal of Medicine, 280, 1261.

LEVINE, I.M., EsTeS, J.W. \& LoONEY, J.M. (1968) Hereditary neurological disease with acanthocytosis. A new syndrome. Archives of Neurology (Chicago), 19, 403.

Lloyd, J.K. \& MULLER, D.P.R. (1972) The management of abetalipoproteinaemia in childhood. Protides of the biological fluids. Proceedings of the 19th Colloquium (1971) Pergamon Press, Oxford and New York. 
O'Brien, J.S. (1967) Cell membranes-composition; structure; function. Journal of Theoretical Biology, 15, 307.

Schwartz, J.F., Rowland, L.P., Eder, H., Marks, P.A., Osserman, E.F., Hirschberg, E. \& ANDERson, H. (1963) Bassen-Kornzweig syndrome: deficiency of serum betalipoprotein. A neuromuscular disorder resembling Friedreich's ataxia associated with steatorrhoea, acantho- cytosis, retinitis pigmentosa and a disorder of lipid metabolism. Archives of Neurology (Chicago), 8, 438.

Sobrevilla, L.A., Goodman, M.L. \& Kane, C.A. (1964) Demyelinating central nervous system disease macular atrophy and acanthocytosis (Bassen-Kornzweig syndrome). American Journal of Medicine, 37, 821.

\title{
Drug-induced hyponatraemia in psychogenic polydipsia
}

\author{
VED V. Gossain* \\ M.D., F.R.C.P.(C), F.A.C.P.
}

\author{
Garrett A. Hagen \\ M.D.
}

\author{
M. SUgaWARA \\ M.D.
}

\begin{abstract}
Veterans Administration Hospital and the Department of Internal Medicine, St Louis University School of Medicine, St Louis, Missouri, U.S.A.
\end{abstract}

\begin{abstract}
Summary
Two patients with psychogenic polydipsia developed hyponatraemia, one in association with administration of hydrochlorothiazide and the other with that of tolbutamide. It is suggested that the increased fluid intake in such patients may make them more susceptible to the development of hyponatraemia from thiazide or sulphonylurea compounds.

\section{Introduction}

Development of clinical hyponatraemia in patients with psychogenic polydipsia is a rare occurrence (Langgard and Smith, 1967; Hobson and English, 1963). Sulphonylurea compounds (Garcia, Miller and Moses, 1971; Hagen and Frawley, 1970) or thiazides (Fuisz, Lauler and Cohen, 1962; Fichman et al., 1971) have been observed to produce hyponatraemia in patients with normal or excessive water intake. Although patients with psychogenic polydipsia might be expected to develop dilutional hyponatraemia more frequently in association with these drugs, it has seldom been reported (Beresford, 1970; Kennedy and Earley, 1970). Two patients with psychogenic polydipsia are described who presented with acute dilutional hyponatraemia, one in associa-

Requests for reprints: Dr G. A. Hagen, Unit III Medical Service, V.A. Hospital, St Louis, Missouri 63125, U.S.A.

* Address correspondence to: Department of Medicine, College of Human Medicine, B234 Life Sciences I, Michigan State University, E. Lansing, Michigan 48824, U.S.A.
\end{abstract}

tion with hydrochlorothiazide, and the other with tolbutamide.

\section{Case report}

Case 1

A 54-year-old white male with chronic schizophrenia and essential hypertension was first seen by G.A.H. in 1972 on the Psychiatric Service of the St Louis Veterans Administration Hospital (Jefferson Barracks Division) after treatment with hydrochlorothiazide $50 \mathrm{mg}$ daily for 5 days. The patient was extremely weak and mentally obtunded, although able to respond to questions. Blood pressure was $110 / 70 \mathrm{mmHg}$, and pulse $84 / \mathrm{min}$. There was no evidence of dehydration. The serum $\mathrm{Na}$ level was $106, \mathrm{~K} \mathrm{1} \cdot 7, \mathrm{Cl} 57$, and $\mathrm{CO}_{2} 34 \mathrm{mEq} / \mathrm{l}$. Serum and urine osmolality were 240 and $115 \mathrm{mmol} / \mathrm{kg}$ respectively. Hydrochlorothiazide was discontinued and with fluid restriction serum electrolyte levels gradually returned to normal and urine osmolality increased to $648 \mathrm{mmol} / \mathrm{kg}$. It was also observed that the patient's daily fluid intake averaged 6-8 litres and a diagnosis of compulsive polydipsia was made. The blood pressure returned to its previous level of $190 / 110 \mathrm{mmHg}$ which was controlled by administration of methyldopa $250 \mathrm{mg}$ q.i.d. and the patient was discharged. He continued to take methyldopa and did well until December 1974, when he was readmitted to the Medical Service because of blood 